several copies are sent out each month to postal subscribers. Extra sheets are prepared as necessary for topical phenomena such as comets.

Other initiatives in recent years include summer workshops for children, where they have made such devices as sundials, planispheres or simple solar-system models. And there have been a couple of weekend astronomy courses for amateur astronomers.

This is a purely public observatory. The telescope is not for use by the staff, but by the public; and on a clear winter evening it is not uncommon for over a hundred people to look through it. The staff never get a chance! We content ourselves instead with watching the faces of visitors who are getting perhaps their first experience of that "wonder and beauty."

\title{
POPULARIZING ASTRONOMY AT PUBLIC OBSERVATORIES IN WEST GERMANY
}

\author{
Hans L. Neumann \\ Frankfurt Public Observatory and Friedrich-Dessauer-Gymnasium \\ Bismarkstrasse 68, D-6050 Offenbach, F.R. Germany
}

\section{Introduction}

Based on the pedagogical ideas of A. Diesterweg, a number of science associations have been founded since about 1880 under the name of URANIA; astronomy has been one of their subjects. In the 1920-1930's, the works of Bruno H. Bürgel and Robert Henseling initiated the founding of many more local and regional associations and of public observatories all over the country. But most of the currently active associations were founded to answer the sharp increase of general interest that followed the early successes and spectacular results of space science.

Aims of the associations always have been manyfold:

- to share a fine hobby with like-minded people;

- to participate theoretically or practically in scientific research as far as technical and local circumstances allow;

- to offer to the public means and advice for celestial observations, and to share the joy of deep-sky wonders with guests;

- to mediate the progress, and the results of astronomical research to the public.

Public observatories either have developed as a result of an association's activities in popularizing astronomy, or become the center for an association's work where both internal (amateur, scientific, social) and external (public) interests can be followed. 
A list of 130 associations and public observatories has been compiled for this report from recent sources (3-6). 75 out of some 100 of them answered my questionnaire.

\section{Distribution}

The regional distribution of all the 130 associations and public observatories shows strong correlation to the general population distribution in the Federal Republic of Germany. As light pollution depends on population density too, the correlation generates severe restrictions on observational activities at most places.

\section{Structure}

Of the 75 associations that answered the questionnaire,

- 47 have the standing of a registered association,

- 11 are installations of communities, counties, or other corporations,

-6 are private initiatives of single persons,

-10 have a permanent full-time staff (including administration) of 1 to 8 people.

The sizes of the associations vary strongly from about 20 to more than 2600 members, and show a dependence on regional population as well as on the age of an association. The number of volunteers in the public programs ranges from very few to about 50 respectively.

\section{Instruments}

Though refractors of approximately $5 \mathrm{~cm} \mathrm{(2")} \mathrm{and} \mathrm{reflectors} \mathrm{of} \mathrm{approximately}$ $10 \mathrm{~cm}$ (4") have been the starting instruments for many associations, by now the 20-cm (8") Schmidt-Cassegrain telescopes have become standard equipment. At public observatories, refractors up to $30 \mathrm{~cm}(12$ ") and reflectors up to $75 \mathrm{~cm}$ (30") are installed. Small planetarium projectors are used regularly at least at 12 public observatories. Special educational installations (e.g., exhibitions, demonstration apparatus) have been developed at various places.

\section{General Programs}

Programs for the public usually include

- observing sessions using the telescopes available at the observatory or on loan from association members,

- lectures giving information on general astronomy and on actual events or research progress,

- courses of introductory or practical astronomy or more specialized subjects (telescope making, astrophotography, etc.), often in cooperation with local institutions of adult education. 


\section{School Programs}

In many places, a close cooperation between public observatories or their connected associations and local schools has been developed. Special programs for school classes, sometimes spanning the whole career from kindergarten to senior high school, have been created.

Introductory lectures may feature special items upon arrangement with the teacher to best fit regular lessons. Observing is very important, as only very few schools have telescopes of their own. Media available at public observatories and astronomical associations often are more numerous and elaborate than those in schools.

\section{Attendance}

Because of the size and standing of an association and other local circumstances, the numbers of public events and of participants varies widely. We cannot check for the ages or other structure of the attendance. Generally, young people form a good fraction.

In total, during 1987 more than 850 amateur astronomers of 60 associations introduced well over 181,000 people to astronomy, running over 5500 events in a wide variety of ways. Some 27,000 more people attended the 1300 events offered by the 9 communal astronomical institutions. The numbers provided give lower limits only, as statistical data are incomplete.

\section{Financing}

Public observatories generally are non-profit and self-preserving organizations. Public support in most cases is negligible compared with members' contributions and donations, though for a very small number of associations it provides up to 80 per cent of the budget.

\section{References}

1. Special inquiry for this report.

2. Personal information from several associations.

3. Manfroid, J. and Heck, A. International Directory of Astronomical Associations. Strasbourg: Centre de Données, 1988.

4. Vercoutter, Ph. A. J., Directory of European Observatories. Ieper: Astronomy Contact Group, 1988.

5. Koch B., Th. Jurriens, and J. Meeus Sternführer 1988. Düsseldorf: Treugesell, 1988.

6. Various reports in: Sterne und Weltraum. München, 1985-1988. 